\title{
ANALISIS DAERAH RAWAN KECELAKAAN DI RUAS JALAN PALANGKA RAYA - TANGKILING
}

\author{
Devia \\ Jurusan Teknik Sipil, Universitas Palangka Raya \\ Email: deviadev90@gmail.com
}

\begin{abstract}
ABSTRAK
Jumlah angka kecelakaan lalu lintas di Ruas Jalan Palangka Raya - Tangkiling semakin meningkat hal ini terbukti bahwa tiap tahun terjadi peningkatan. Ruas tersebut berfungsi sebagai jalan penghubung antar kabupaten dan merupakan jalan arteri primer. Dengan terjadinya kecelakaan pada ruas jalan tersebut maka akan mengakibatkan menurunnya kinerja jalan tersebut tujuan dalam penelitian ini adalah untuk menganalisis daerah rawan kecelakaan serta penyebabnya agar dapat diketahui penanganan pada daerah rawan kecelakaan. Penelitian ini bertujuan untuk mengetahui titik blackspot dan mengetahui variabel apa saja yang berpengaruh terhadap tingkat kecelakaan (AR) serta dapat memberikan penanganan pada lokasi rawan kecelakaan. Uji statistik berupa uji regresi linear berganda dengan program SPSS. Berdasarkan hasil analisis bahwa Tingkat Kecelakaan (AR) tertinggi pada STA 3+000 - 4+000. Dan faktor yang berpengaruh adalah variabel Tata Guna Lahan, berdasarkan Tipe Tabrakan, berdasarkan Jenis Kelamin dan Kecepatan Kendaraan lebih dari kecepatan rata-rata.. Oleh karena itu perlu memperhatikan penggunaan lahan disamping jalan agar Ruang Manfaat Jalan yang bebas dari segala macam bangunan.
\end{abstract}

\section{Kata Kunci: daerah rawan kecelakaan, penyebab kecelakaan, penanganan kecelakaan}

\begin{abstract}
The number of traffic accident on roads from Palangka Raya to Tangkiling has increased. This is proved that it has increased every year. The road is functioned as the linking road among districts and it is also utilized as the main artery road. Accidents that are occurred in some parts of that road decrease the performance of the road. The aim of this study is to analyze the accident-prone area and its causes so that we are able to identify handings of that area. This study aims to identify the blackspot points and variables that affect the accident rate (AR) as well as provide handlings for the accident-prone area. The statistic test was multiple linear regression tests using SPSS program. Based on the result of the analysis, it was found that the highest accident rate (AR) on the range of STA 3+000 to 4+000 on Tjilik Riwut road in Palangka Raya. Changes on land use, type of accident, gender, and high speed of vehicle make the accident rate increase. Therefore it is necessary to pay attention to the use of land beside the road so that the Road Benefit Space is free of all kinds of buildings.
\end{abstract}

Keywords: Accident Prone Area, cause of the accident, accident handlings

\section{PENDAHULUAN}

Kecelakaan lalu lintas merupakan masalah yang membutuhkan penanganan serius karena mengakibatkan kerugian secara materi hingga korban jiwa. Peningkatan kecelakaan lalu lintas, berbanding lurus dengan terjadinya peningkatan pergerakan, tingkat kemudahan kepemilikan kendaraan pribadi dan rendahnya tingkat disiplin berlalu lintas sehingga mengakibatkan kecelakaan 
lalu lintas. Beberapa perbaikan dan kebijakan yang dilakukan oleh pemerintah dengan berbagai pihak untuk mengurangi tingkat kecelakaan lalu lintas masih belum optimal. Beberapa kebijakan yang dilakukan pemerintah untuk mengurangi kecelakaan lalu lintas yaitu memberi sanksi denda kepada pelanggar lalu lintas, tilang, dan hukuman terberat berupa kurungan penjara.

Angka kecelakaan lalu lintas pada kota Palangka Raya terjadi peningkatan, hal itu terbukti bahwa tiap tahun jumlah angka kecelakaan pada ruas jalan di kota Palangka Raya semakin meningkat. Salah satu ruas jalan yang sering terjadi kecelakaan lalu lintas yaitu ruas jalan Palangka Raya - Tangkiling, yang mana ruas jalan tersebut berfungsi sebagai jalan penghubung antar kabupaten dan merupakan jalan arteri primer.

Dengan terjadinya kecelakaan pada ruas jalan Palangka Raya - Tangkiling tersebut maka akan mengakibatkan menurunnya kinerja jalan tersebut. Dalam meningkatkan keamanan lalu lintas di jalan terdapat 3 (tiga) bagian yang saling berhubungan dengan operasi lalu lintas, yakni: pengemudi, kendaraan, dan jalan raya.

Penyebab kecelakaan lalu lintas pada dasarnya ada tiga faktor yaitu faktor pertama adalah hubungan manusia dengan jalan dan lingkungan yang merupakan pemahaman faktor manusia (human factor), faktor kedua adalah hubungan antara manusia dengan kendaraan (human machine interface) yang merupakan pemahaman terhadap faktor ergonomik. Dan faktor ketiga yaitu hubungan antara kendaraan dengan jalan dan lingkungan yang merupakan pemahaman faktor fisik dan rekayasa jalan.

Frekuensi kejadian kecelakaan sebagian besar disebabkan oleh faktor manusia itu sendiri yaitu pengemudi yang dominan melakukan pelanggaran lalu lintas. Dari data yang ada di kepolisian ruas jalan di Kota Palangka Raya yang mengalami kecelakaan lalu lintas terbanyak adalah ruas jalan Tjilik Riwut dan diketahui penyebab terbesar kecelakaan lalu lintas adalah faktor pengemudi. Dengan banyaknya lokasi kecelakaan (Blackspot) pada jalan Tjilik Riwut akan berakibat menurunnya kinerja ruas jalan tersebut, mengurangi kenyamanan dan bahkan membahayakan kenyamanan dan keselamatan pengguna jalan. Untuk mengatasi hal tersebut, maka studi daerah rawan kecelakaan diruas jalan tersebut perlu dilakukan dan dilakukan penanganan untuk mengurangi jumlah dan tingkat kecelakaan yang ada.

Berdasarkan Keputusan Menteri Pekerjaan Umum No. 567/KPTS/M/2009 tentang Rencana Umum Jaringan Jalan Nasional dan UU no 38 Tahun 2004 tentang Jalan yaitu Bina Marga memiliki komitmen dalam mewujudkan penyelenggaraan jalan yang berkeselamatan. Tata guna lahan, volume lalu lintas dan karakteristik pengemudi merupakan faktor-faktor paling besar yang mempengaruhi terjadinya kecelakaan (Yuren, 2002).

Pada ruas jalan tersebut rawan terjadi kecelakaan lebih banyak pada jalan lurus akibat dari kecepatan yang tinggi dan tidak dapat dikendalikan oleh pengemudi kendaraan serta dengan aktivitas disekitar ruas jalan tersebut yang sangat tinggi.

Berdasarkan uraian di atas, diyakini bahwa upaya untuk mengurangi kecelakaan agar dapat optimal adalah dengan mengetahui daerah rawan kecelakaan dan penyebab kecelakaan serta penanganan pada daerah rawan kecelakaan.

\section{LANDASAN TEORI}

Daerah yang mempunyai angka kecelakaan tinggi, resiko kecelakaan tinggi dan potensi kecelakaan tinggi pada suatu ruas jalan dapat disebut daerah rawan kecelakaan. Penggolongan ruas jalan tertentu dikatakan masuk dalam kategori daerah rawan kecelakaan lalu lintas, memiliki beberapa istilah yang digunakan sebagai kriteria.

$R=\quad 365 \stackrel{A}{A} \times \frac{10}{T} \times 0^{8}$

di mana $\mathrm{A}=$ Jumlah Kecelakaan Kendaraan, $\mathrm{T}=$ Periode Data Kecelakaan (Tahun), V = LHR, L = Panjang Jalan (Km).

Untuk menganalisis titik kecelakaan tertinggi (blackspot) yang terjadi di daerah yang akan ditinjau. Angka Ekivalen Kecelakaan adalah angka untuk pembobotan kelas kecelakaan. Perhitungan AEK terikat dengan tingkat fatalitas kecelakaan lalu lintas dan jumlah kejadian kecelakaan yang menyebabkan kerugian material.

Badan Penelitian dan Pengembangan Departemen Kimpraswil (2004), telah membuat formula matematik untuk menghitung nilai AEK 
(Angka Ekivalen Kecelakaan) dengan rumus sebagai berikut:

Tabel 1 Angka Ekivalen Kecelakaan

\begin{tabular}{llc}
\hline \multicolumn{1}{c}{ Kelas } & \multicolumn{1}{c}{ Keterangan } & Bobot \\
Kecelakaan & Kecelakaan Fatal & 12 \\
$\begin{array}{l}\text { Meninggal } \\
\text { Dunia (MD) }\end{array}$ & 3 \\
$\begin{array}{l}\text { Luka Berat } \\
(\text { LB) }\end{array}$ & $\begin{array}{l}\text { Kecelakaan } \\
\text { dengan Luka } \\
\text { Berat }\end{array}$ & 3 \\
Luka & $\begin{array}{l}\text { Kecelakaan } \\
\text { dengan Luka }\end{array}$ & 3 \\
Ringan (LR & $\begin{array}{l}\text { Ringan } \\
\text { Kerugian } \\
\text { Kerusakan }\end{array}$ & 1 \\
Material (K) & Material & \\
\hline
\end{tabular}

Sumber : Departemen Permukiman dan Prasarana Wilayah (2004)

Rumus Angka Ekivalen Kecelakaan (AEK):

$\mathrm{EAN}=12 \mathrm{MD}+3 \mathrm{LB}+3 \mathrm{LR}+\mathrm{K}$

Jenis dan bentuk kecelakaan dapat diklasifikasikan menjadi 5 (lima) yaitu : kecelakaan berdasarkan korban kecelakaan, kecelakaan berdasarkan lokasi kejadian, kecelakaan berdasarkan waktu terjadinya kecelakaan, kecelakaan berdasarkan posisi kecelakaan dan kecelakaan berdasarkan jumlah kendaraan yang terlibat.

Hobbs (1979) mengelompokkan faktorfaktor penyebab kecelakaan menjadi tiga kelompok, yaitu faktor pemakai jalan (manusia), faktor kendaraan, faktor jalan dan lingkungan.

Tabel 2 Komposisi Faktor Penyebab Kecelakaan

\begin{tabular}{|c|c|c|}
\hline $\begin{array}{c}\text { Faktor } \\
\text { Penyebab }\end{array}$ & Uraian & $\begin{array}{c}\text { Persentase } \\
(\%)\end{array}$ \\
\hline Pengemudi & $\begin{array}{lr}\text { Lengah, } & \text { mengantuk, } \\
\text { tidak } & \text { terampil, } \\
\text { mabuk, } & \text { kecepatan } \\
\text { tinggi, tidak menjaga } \\
\text { jarak, } & \text { kesalahan } \\
\text { pejalan, } & \text { gangguan } \\
\text { binatang } & \\
\end{array}$ & 93,52 \\
\hline Kendaraan & $\begin{array}{lr}\text { Ban } & \text { Pecah, } \\
\text { kerusakan } & \text { sistem } \\
\text { rem, } & \text { kerusakan } \\
\text { sistem } & \text { kemudi, } \\
\text { as/kopel lepas, sistem } \\
\text { lampu r } & \text { tidak } \\
\text { berfungsi } & \\
\end{array}$ & 2,76 \\
\hline
\end{tabular}

\begin{tabular}{cll}
\hline $\begin{array}{c}\text { Faktor } \\
\text { Penyebab }\end{array}$ & \multicolumn{1}{c}{ Uraian } & $\begin{array}{c}\text { Persentase } \\
(\%)\end{array}$ \\
\hline Jalan & $\begin{array}{l}\text { Persimpangan jalan } \\
\text { sempit, akses yang }\end{array}$ & 3,23 \\
& tidak dikontrol / \\
& dikendalikan, marka & \\
& jalan kurang/tidak \\
& jelas, tidak ada rambu \\
& batas kecepatan, \\
& permukaan jalan licin \\
\hline Lingkungan & Lalu lintas campuran \\
& antara kendaraan \\
& cepat dengan \\
& kendaraan lambat, \\
& interaksi/ campur \\
antara dengan & \\
pejalan, pengawasan \\
dan penegakan \\
hukum belum efektif, \\
pelayanan gawat \\
darurat yang kurang \\
cepat. Cuaca : gelap, \\
hujan, kabut, asap.
\end{tabular}

Sumber : Direktorat Jenderal Perhubungan Darat (1998)

Analisis statistik dimanfaatkan untuk melihat sejauh mana suatu tipe kecelakaan serta faktor lainnya dianggap dominan pada suatu lokasi kecelakaan sehingga dapat diambil langkah penanggulangan daerah rawan kecelakaan.

Lokasi Rawan Kecelakaan Berdasarkan UCL (Upper Control Limit):

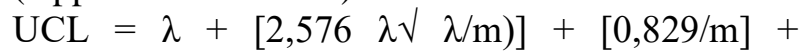
$[1 / 2 \mathrm{~m}]$

di mana $\mathrm{UCL}=$ garis kendali batas, $\lambda=$ rata-rata tingkat kecelakaan dalam satuan kecelakan per eksposure, $\mathrm{m}=$ satuan eksposure $(\mathrm{km})$.

\section{METODE PENELITIAN}

Penelitian dilakukan di Kota Palangka Raya yaitu pada ruas Palangka Raya - Tangkiling yang mengalami kecelakaan lalu lintas. Sampel yang diambil adalah titik daerah rawan kecelakaan pada ruas jalan yang diteliti.

Data sekunder didapatkan dengan cara mengumpulkan dari instansi-instansi terkait. Data ini berupa: 
a. Data kecelakaan lalu lintas tahun 2010-2014, berupa lokasi kecelakaan, faktor penyebab kecelakaan, tipe tabrakan, jenis kendaraan/pengguna jalan yang terlibat kecelakaan, usia pelaku dan kelas kecelakaan yang diperoleh dari Polres Palangka Raya

b. Data volume lalu lintas

c. Peta Lokasi

d. Data Status Jalan

Data primer diperoleh langsung dari survai lapangan antara lain data kelengkapan sarana dan prasarana (rambu, median, guard rail, dll), data geometrik dan kondisi jalan.

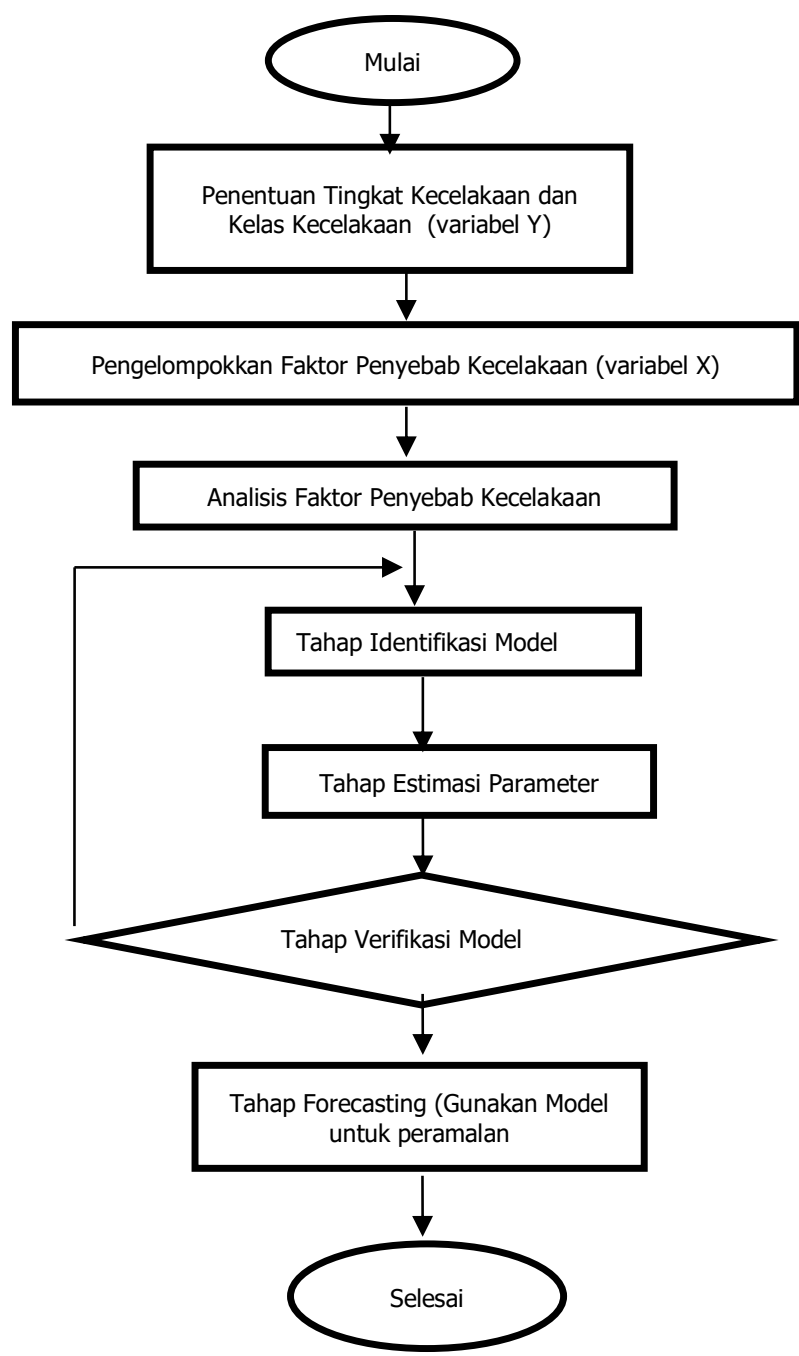

Gambar 1. Bagan Alir Analisis

Data kecelakaan lalu lintas yang diperoleh dari Kepolisian Resort Kota Palangka Raya selama kurun waktu tertentu dianalisis untuk menentukan tingkat kecelakaan lalu lintas. Untuk menentukan daerah rawan kecelakaan dilakukan dengan membandingkan Tingkat Kecelakaan (AR) dan Angka Ekivalen Kecelakaan (EAN) dengan UCL
(Upper Control Limit) yaiu AR > UCL dan/atau EAN > UCL maka lokasi ini daerah rawan kecelakaan. Angka Ekivalen kecelakaan (EAN) merupakan suatu carau ntuk mengurutkan prioritas penanganan dengan cara pembobotan setiap kelas kecelakaan. Angka pembobotan yang digunakan dalam EAN .(berdasarkan tingkat kefatalan) .Data kecelakaan dilengkapi dengan data jumlah Meninggal Dunia (MD), Luka Berat (LB), Luka Ringan (LR), Kerusakan Material.

Berdasarkan tinjauan teori dan penelitian terdahulu, variabel yang akan diamati pengaruhnya terhadap Tingkat Kecelakaan pada daerah rawan kecelakaan, antara lain:
a. Tipe tabrakan
b. Tata guna lahan
c. Pelaku kecelakaan (Umur dan jenis kelamin)
d. Jenis kendaraan
e. Geometrik jalan
f. Perlengkapan jalan

Analisis statistik dimanfaatkan untuk melihat sejauh mana suatu tipe kecelakaan serta faktor lainnya dianggap dominan pada suatu lokasi kecelakaan sehingga dapat diambil langkah penanggulangan daerah rawan kecelakaan serta untuk melihat variabel yang memiliki pengaruh kuat dalam kecelakaan lalu lintas, dan pertambahan volume lintas. Langkah-langkah analisis statistik diatas, juga dapat digambarkan dalam flow chart pada Gambar 1.

Dalam menentukan tingkat kecelakaan lokasi rawan kecelakaan diperlukan data-data yang dapat mendukung agar diketahui lokasi mana yang mempunyai tingkat kecelakaan yang tinggi dan tingkat fatalitas yang tinggi. Data yang dimaksud adalah jumlah kecelakaan pada lokasi studi, data LHR dan kelas kecelakaan. Data tersebut diolah dan didapatkan lokasi rawan kecelakaan.

Pengujian statistik antar variabel terikat dan bebas, untuk mengetahui hubungan dan keterikatan antar variabel. Analisis antara variabel terikat dan bebas menggunakan analisis regresi dan teknik korelasi dalam hal ini penulis menggunakan program SPSS. Penggunaan program ini sangat membantu proses analisis karena tidak memerlukan perhitungan manual, sehingga lebih efektif dan efisien. 


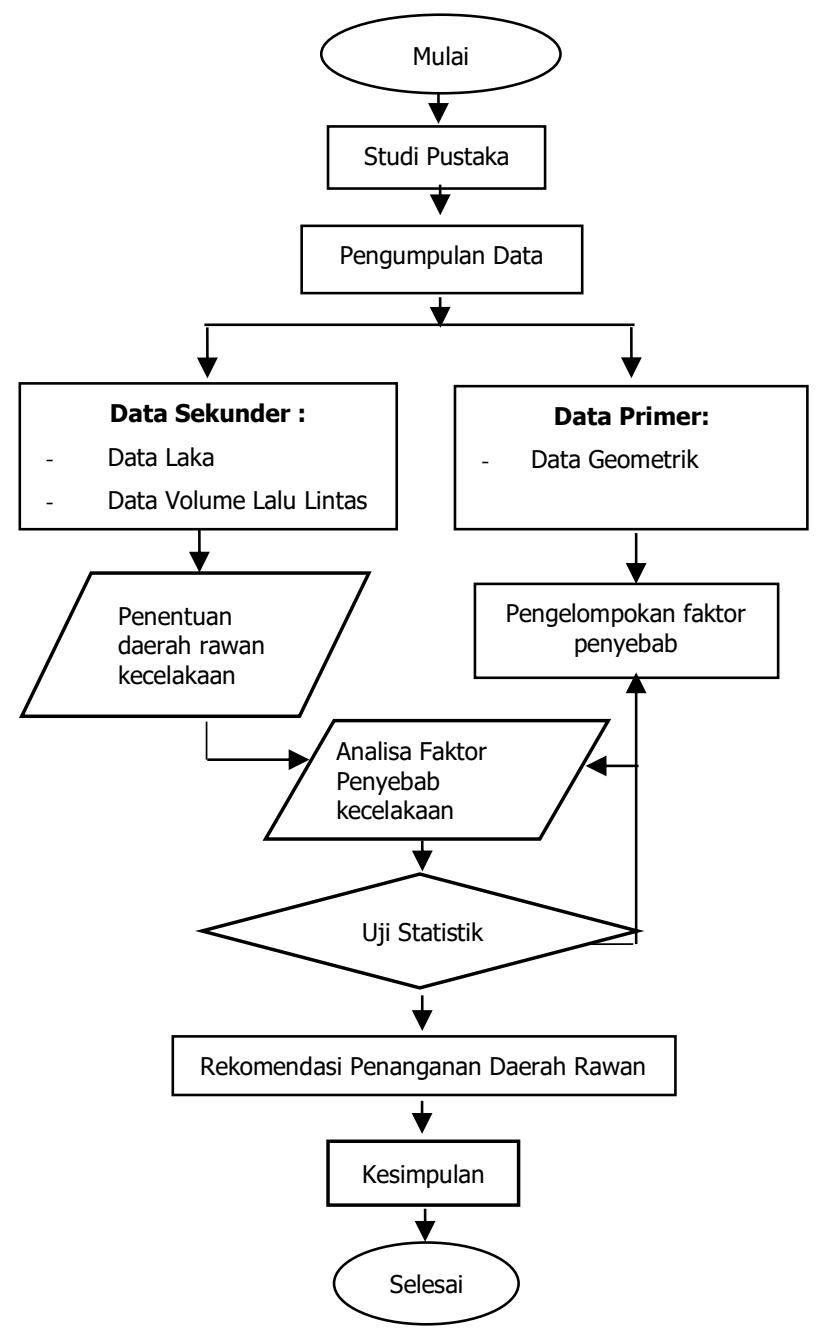

Terdapat metode atau langkah kerja dari penelitian tentang penanganan lokasi rawan kecelakaan pada ruas Palangka Raya-Tangkiling. Tujuan dari metode penelitian ini adalah untuk mengetahui serta merencanakan langkah-langkah kerja penelitian dari studi literatur, pengumpulan data, analisis data, penanganan dan rekomendasi sampai mendapatkan kesimpulan dan saran, sebagaimana Gambar 2:

\section{HASIL PEMBAHASAN}

Berdasarkan hasil analisis pada daerah rawan kecelakaan pada Tabel 3. Variabel tidak bebas dalam analisa ini ditentukan melalui jumlah korban yang meninggal dunia, luka berat, luka ringan dan kerugiam material serta jumlah EAN disusun dalam Tabel 4.

Gambar 2. Bagan Alir Penelitian

Tabel 3. Hasil Perhitungan Lokasi Rawan Kecelakaan

\begin{tabular}{cccccc}
\hline STA & Jumlah Kecelakaan & Jumlah EAN & UCL EAN & AR & UCL AR \\
\hline $0-1$ & 24 & 155 & 187,43 & 301,83 & 278,88 \\
$3-4$ & 39 & 365 & 187,43 & 490,47 & 278,88 \\
$10-11$ & 11 & 132 & 69,74 & 172,36 & 89,59 \\
$11-12$ & 11 & 129 & 69,74 & 172,36 & 89,59 \\
$13-14$ & 7 & 75 & 69,74 & 109,68 & 89,59 \\
$14-15$ & 7 & 87 & 69,74 & 109,68 & 89,59 \\
$28-29$ & 6 & 63 & 69,74 & 94,01 & 89,59 \\
$30-31$ & 7 & 93 & 69,74 & 109,68 & 89,59 \\
$31-32$ & 7 & 75 & 69,74 & 109,68 & 89,59 \\
$32-33$ & 8 & 72 & 69,74 & 125,35 & 89,59 \\
\hline
\end{tabular}

Sumber: Hasil Analisis

Tabel 4. Kelas Kecelakaan pada Lokasi Kecelakaan

\begin{tabular}{ccccc}
\hline STA & Meninggal Dunia & Luka Berat & Luka Ringan & Kerugian Materi \\
\hline $00+000-01+000$ & 1 & 2 & 32 & 41 \\
$03+000-04+000$ & 7 & 4 & 66 & 71 \\
$10+000-11+000$ & 5 & 0 & 17 & 21 \\
$11+000-12+000$ & 4 & 1 & 18 & 24 \\
$13+000-14+000$ & 4 & 3 & 2 & 12 \\
$14+000-15+000$ & 4 & 3 & 5 & 15 \\
\hline
\end{tabular}




\begin{tabular}{ccccc}
\hline STA & Meninggal Dunia & Luka Berat & Luka Ringan & Kerugian Materi \\
\hline $28+000-29+000$ & 1 & 1 & 12 & 12 \\
$30+000-31+000$ & 1 & 1 & 21 & 15 \\
$31+000-32+000$ & 1 & 0 & 17 & 12 \\
$32+000-33+000$ & 0 & 0 & 20 & 12 \\
\hline
\end{tabular}

Sumber: Kepolisian Resort Palangka Raya

Tabel 5. Variabel tidak bebas (Tingkat Kecelakaan dan Kelas Kecelakaan)

\begin{tabular}{ccccccc}
\hline & \multicolumn{7}{c}{$Y$} & \multicolumn{2}{l}{} \\
\cline { 2 - 7 } No & $\begin{array}{l}\text { Tingkat } \\
\text { Kecelakaan } \\
(A R)\end{array}$ & $\begin{array}{l}\text { Kelas } \\
\text { Kecelakaan } \\
\text { Meninggal } \\
\text { Dunia }\end{array}$ & $\begin{array}{l}\text { Kelas } \\
\text { Kecelakaan } \\
\text { Luka Berat }\end{array}$ & $\begin{array}{l}\text { Kelas } \\
\text { Kecelakaan } \\
\text { Luka Ringan }\end{array}$ & $\begin{array}{l}\text { Kecelakaan } \\
\text { Kerugian } \\
\text { Materi }\end{array}$ & $\begin{array}{l}\text { Kelas } \\
\text { Kecelakaan } \\
\text { EAN }\end{array}$ \\
\hline 1 & 24 & 1 & 2 & 32 & 41 & 155 \\
2 & 39 & 7 & 4 & 66 & 71 & 365 \\
3 & 11 & 5 & 0 & 17 & 21 & 132 \\
4 & 11 & 4 & 1 & 18 & 24 & 129 \\
5 & 7 & 4 & 3 & 2 & 12 & 75 \\
6 & 7 & 4 & 3 & 5 & 15 & 87 \\
7 & 6 & 1 & 1 & 12 & 12 & 63 \\
8 & 7 & 1 & 1 & 21 & 15 & 75 \\
9 & 7 & 1 & 0 & 17 & 12 & 72 \\
10 & 8 & 0 & 0 & 20 & 12 & 93 \\
\hline
\end{tabular}

Sumber: Hasil Analisis

Dari Tabel 5 terlihat bahwa jumlah persamaan $\mathrm{Y}$ sebanyak 6 macam yang nantinya dapat diketahui variabel bebas mana yang mempengaruhi variabel tidak bebas tersebut $(\mathrm{Y})$ dari masing-masing variabel.

Dari hasil analisis terlihat bahwa Model Regresi Tingkat Kecelakaan variabel bebas Tata Guna Lahan, Tipe Tabrakan, Jenis Kelamin dan Kecepatan Kendaraan secara simultan atau bersama-sama berpengaruh terhadap Tingkat Kecelakaan. Sedangkan secara parsial variabel Tata Guna Lahan Berpengaruh terhadap Tingkat Kecelakaan.

Model regresi Kelas Kecelakaan Luka Ringan yang mempengaruhi variabel bebasnya adalah Tata Guna Lahan yang berarti semakin meningkat aktivitas di sekitar daerah rawan kecelakaan maka Tingkat Kecelakaan semakin meningkat.

Model Regresi Kelas Kecelakaan Kerugian Materi yang mempengaruhi variabel bebas secara bersama-sama adalah variabel bebas Tipe Tabrakan, Jenis Kelamin dan Lebar Jalan berpengaruh dalam Model Regresi Kelas Kecelakaan Kerugian Materi. Sedangkan secara parsial variabel Tata Guna Lahan Berpengaruh terhadap Kelas Kecelakaan Kerugian Materi.
Berdasarkan penelitian terdahulu bahwa Tata Guna Lahan berpengaruh terhadap terjadinya tingkat kecelakaan pada daerah rawan kecelakaan (Aqli,2010).

Lokasi Daerah Rawan Kecelakaan Palangka Raya - Tangkiling dengan peringkat 3 tertinggi berada pada lokasi:

a. Ruas Jalan Tjilik Riwut pada STA 3+000 s/d 4+000 dengan nilai Tingkat Kecelakaan (AR) > Upper Control Limit (UCL) AR (490,47 > 278,88) dan nilai Equivalent Accident Number $($ EAN) > Upper Control Limit (UCL) EAN (365 $>187,43)$.

b. Ruas Jalan Tjilik Riwut pada STA $0+000$ s/d 1+000 dengan nilai Tingkat Kecelakaan (AR) > Upper Control Limit (UCL) AR (301,83 > 278,88) dan nilai Equivalent Accident Number $($ EAN) $>$ Upper Control Limit (UCL) EAN (155 $<187,43)$.

c. Ruas Jalan Palangka Raya - Tangkiling pada STA $10+000 \mathrm{~s} / \mathrm{d} 11+000$ dan pada STA $11+000$ s/d 12+000 dengan nilai Tingkat Kecelakaan (AR) > Upper Control Limit (UCL) AR (172,36 $>$ 89,59) dan nilai Equivalent Accident Number $($ EAN) > Upper Control Limit (UCL) EAN (132 $>69,74$ ) dan pada STA $11+000$ s/d 12+000 nilai Equivalent Accident Number (EAN) > Upper Control Limit (UCL) EAN (129> 69,74). 


\section{PENUTUP}

\section{Kesimpulan}

Dari hasil data, analisa dan pembahasan yang telah disampaikan pada bagian sebelum dapat ditarik kesimpulan sebagai berikut.

1. Angka Kecelakaan tertinggi yaitu pada ruas jalan Tjilik Riwut STA 3+000 s/d 4+000 dengan nilai Tingkat Kecelakaan (AR) 490,47 lebih besar dari Upper Control Limit (UCL) 278,88. Angka Ekivalen Kecelakaan (EAN) yang berhubungan dengan tingkat kefatalan tertinggi yaitu pada ruas Tjilik Riwut STA 3+000 s/d 4+000 dengan nilai Angka Ekivalen Kecelakaan (AEK) 365 lebih besar dari Upper Control Limit (EAN) 187,43.

2. Dari hasil permodelan Regresi untuk Tingkat Kecelakaan (AR) secara bersama-sama dalam Regresi Linear bahwa variabel bebas Tata Guna Lahan, Tipe Tabrakan, Jenis Kelamin dan Kecepatan Kendaraan berpengaruh dalam Tingkat Kecelakaan. Sedangkan hubungan antara variabel bebas dan terikat yang berpengaruh adalah variabel bebas Tata Guna Lahan.

3. Tata Guna Lahan berpengaruh terhadap tingkat kecelakaan maka perlu memperhatikan penggunaan lahan disamping jalan agar Ruang Manfaat Jalan yang bebas dari segala macam bangunan

\section{DAFTAR PUSTAKA}

Aqli, Z. (2010). Analisis Daerah Rawan Kecelakaan Di Kabupaten Tapin - Kalimantan Selatan. Tesis Program Pascasarjana Teknik Sipil. Universitas Lambung Mangkurat. Banjarmasin

Depkimpraswil. (2004). Pedoman Penanganan Lokasi Rawan Kecelakaan Lalu Lintas. Pedoman Konstruksi dan Bangunan nomor Pd 1-09-2004-B. Jakarta

Ditjen Bina Marga, 2006 (a), Kajian Kebutuhan Pelaksanaan Keselamatan Jalan di Indonesia, Departemen Pekerjaan Umum, Jakarta

Ditjen Bina Marga, 2006 (b), Keselamatan Dalam Penyelenggaraan Transportasi Jalan, Departemen Pekerjaan Umum, Jakarta
Ditjen Bina Marga, (2007), Penyusunan Sistem Manajemen dan Pedoman Keselamatan Jalan dalam Kegiatan Pembangunan Jalan, Departemen Pekerjaan Umum, Jakarta

Ditjen Perhubungan Darat, (2006), Penyusunan Rencana Umum Keselamatan Transportasi Darat, Departemen Pekerjaan Umum, Jakarta Hobbs. (1979) Perencanaan dan Teknik Lalu Lintas. Universitas Gadjah Mada. Yogyakarta

Peraturan Pemerintah Republik Indonesia no 43 tahun 1993 tentang Prasarana dan Lalu Lintas Jalan

Peraturan Pemerintah Nomor 34 Tahun 2006 tentang Jalan

Sayekti, D dan Agus, T. M. (2009) Inspeksi Keselamatan Jalan Studi Kasus Jalan Parangtritis Yogyakarta. Simposium XII FSTPT, Universitas Kristen Petra. Surabaya

Segah, B. (2002). Analisis Karakteristik Daerah Rawan Kecelakaan Lalu Lintas Di Kota Palangka Raya. Tesis Program Pascasarjana Sistem dan Teknik Transportasi. Universitas Gadjah Mada. Yogyakarta

Undang-Undang Republik Indonesia Nomor 38 tahun 2004 tentang Jalan 